\section{Making objective forest stand maps of mixed managed forest with spatial interpolation and multi-criteria decision analysis}

\author{
Sinan Destan ${ }^{(1)}$, Osman Yalçın Yilmaz ${ }^{(2)}$, Abbas Sahin ${ }^{(3)}$
}

Spatial interpolation and multi-criteria decision analysis (MCDA) capabilities of geographic information systems have the potential to create new approaches to forest management. In this study, the regularized spline with tension (RST) interpolation method and ELECTRE TRI MCDA was used to predict forest stand volumes in an area characterized by even-aged stands with heterogeneous structures in Turkey. Sampling data (1050 circular sample plots) were obtained from the National forest inventory. For each species and diameter class, a map of the predicted volume per ha was obtained using the RST method. By repeating the same process for the eight species occurring in the study area, 31 volume maps were produced. The accuracy of these prediction maps was assessed at pixel $(20 \times 20 \mathrm{~m})$ and area scale (per ha). An accuracy of more than $97 \%$ was achieved at the pixel level, whereas a minimum accuracy of $86 \%$ was achieved for the area-based estimations. In addition, predicted values from the above 31 volume maps were compared with the observed values from management plan reports obtained from the Government Institute responsinble for forest management plans. The comparisons showed an accuracy of predictions of $21,14,4$, and $2 \%$ for Calabrian pine, Oriental beech, black pine and oak species, respectively. Following interpolation, volume prediction maps were geo-computed, and a volume-based stand map was produced. The 890 different combinations of species composition and diameter classes were classified according to expert knowledge by the use of ELECTRE TRI MCDA, obtaining a final stand type map representing 70 different profile categories based on species mixture rates and diameter classes for the area analyzed.

Keywords: Regularized Spline with Tension, Multi-Criteria Decision Analysis, Forest Map, Forest Management

\section{Introduction}

Information about extant forest communities is of considerable importance in forest management planning. The stand is the smallest production and silvicultural unit, and the most crucial part of this information. The location of planning units, their size and silvicultural features are used to select management objectives and determine the working cycle, management regulations and silvicultural goals. Thus, the precision of decisions to be implemented and the planning to be

realized are both closely related to the accuracy of the stand maps. Moreover, map accuracy depends on the type of forest inventory, the sample size, and the techniques used to evaluate the inventory results.

Stand maps have previously been produced subjectively (Feng et al. 2006) in conjunction with current forest management practices. In conventional management planning, stands are defined through the planning process. The type of of the management objectives is a component of this process (Gun-

$\square$ (1) Department of Forest Management, Faculty of Forestry, Istanbul University, 34473 Bahçeköy, Istanbul (Turkey); (2) Department of Forest Engineering, Faculty of Forestry, Istanbul University, 34473 Bahçeköy, Istanbul (Turkey); (3) Department of Forest Management, Regional Forest Directorate of Istanbul, Istanbul (Turkey)

@ Sinan Destan (destans@istanbul.edu.tr)

Received: May 18, 2012 - Accepted: Mar 18, 2013

Citation: Destan S, Yilmaz OY, Sahin A, 2013. Making objective forest stand maps of mixed managed forest with spatial interpolation and multi-criteria decision analysis. iForest 6 : 268-277 [online 2013-07-01] URL: http://www.sisef.it/iforest/contents/?id=ifor0099-006

Communicated by: Agostino Ferrara narsson et al. 1998). However, the use of computers has changed this conventional approach, and spatially and temporally dynamic description and treatment units can readily be produced (Holmgren \& Thuresson 1997). Thus, dynamic forest planning can be achieved with the use of geopositioned field plot data and computers (Wallerman et al. 2002).

The sampling methods used in forest inventories vary according to different countries' forestry objectives and forest structures. Systematic sampling methods are recommended for large and homogeneous forest areas and have been implemented in all production and conservation areas of Turkey since 1964. However, if this sampling method is implemented with an insufficient number of sample plots and/or in heterogeneous forests, the results will be highly questionable because they may fail to reflect the true forest composition. Although Sherman (1996), Aurbi \& Debouzie (2000), Flores et al. (2003) and D'Orazio (2003) used remote sensing data to improve the results of such inventories, the desired outcome was never achieved in practice.

Spatial interpolation methods, which have been classified by Li \& Heap (2008) as nongeostatistical, geostatistical and combined, came into use at the end of the 1960s and have been investigated for use in forest management. As described in Akhavan et al. (2010), Guibal (1973) was the first study to use kriging in the forest inventory process. Jost (1993) also used geostatistical methods to compare conventional inventory results based on systematic sampling with the results of the kriging method. Geostatistically based methods that utilize textural information are frequently used to analyze remote-sensing (RS) images (Zawadzki et al. 2005). The quality and quantity of these methods have increased through advances in the computer sciences and in the science of geographical information systems. These methods allow the use of a variety of ecological and technical parameters in the assessment of inventory results.

Palmer et al. (2009) compared the spatial predictions derived from Inverse Distance Weighting (IDW), Partial Least Squares (PLS), Regression Kriging (RK), and Ordinary Kriging (OK) for Pinus radiata mean volume, annual increment and mean top height. Viana et al. (2012) made estimations of the crown biomass of Pinus pinaster stands and aboveground shrubland biomass using forest inventory data, remotely sensed imagery for auxiliary variables and spatial prediction models. These estimations involved the use of RK and OK, Universal Kriging (UK), IDW and Thiessen Polygon estimations. Magnussen et al. (2009) examined the advantages of multiresolution spatial 
models (MRSMs) for large datasets compared with standard algorithms.

Montes et al. (2010) have proposed a method in which the addition of experienced inventory data areas are combined with environmental information. Nanos et al. (2004) also used a geostatistical approach for the prediction of diameter distributions in stands of Pinus pinaster Ait. Tang \& Bian (2009) successfully applied a forest site evaluation method which integrates a geographic information system (GIS) and a spatial interpolation method (kriging) in geostatistics

Köhl et al. (2006) suggested the use of aerial photographs, satellite images, site data, and thematic maps in the analysis and modeling of survey plans. Mandallaz (1991) compared different geostatistical methods in forest inventory creation. Höck et al. (1993) evaluated the kriging method using site index data. Holmgren \& Thuresson (1997) used kriging and remote sensing to predict stand volumes.

Heikkinen (2006) and many other researchers reported that the determination of sampling errors was a serious problem associated with systematic sampling. To obtain greatly improved results from systematic sampling and inventory measurements, the use of additional explanatory environmenta variables has been initiated (Lappi \& Kangas 2006).

Recently, the production of stand maps based on GIS has started to develop forest management planning in Turkey. Since 2004, computers have been used to perform stand type delineations and generalizations with classical and subjective operator-oriented methods and to produce digital maps of high cartographic quality. However, as emphasized by Burrough (2001), the spatial and statistical analysis capabilities of GIS have not been fully explored and exploited yet. In contrast, GIS capabilities, combined with different spatial interpolation methods and multi-criteria decision analysis (MCDA), are being developed and implemented in numerous disciplines.

ELECTRE (ELimination Et Choix Traduisant la REalité - Elimination and Choice Expressing the Reality) is family of methods derived from MCDA that associate members to create an alternative set of relationships within the system, and then compare the alternatives obtained to solve the problem under investigation. The main advantage of these methods is that the optimal solution is not subjective, avoiding classical approaches based on individual experience and intuition. Diverse ELECTRE methods differ in minor respects. For instance, ELECTRE TRI was created to solve selection and assignment problems.

A review of more than 250 papers in the forestry literature over the past 30 years showed that 9 different versions of MCDA were applied to 9 different forestry topics (wood production, biodiversity, sustainability, reforestation, regional planning, forest industry, risks, and other subjects - Balteiro \& Romero 2008). A variant of the ELECTRE method was recommended by Kangas et al. (2001) who discussed the application of the ELECTRE III and PROMETHEE II methods in 17 forest activity areas. Mendoza \& Martins (2006) critically reviewed the MCDA methods applied to the management of forests and other natural resources, describing the nature of these models and their inherent strengths and limitations. Jayanath \& Gamini (2009) also provided a comprehensive literature review in forest management evaluating 9 different types of MCDA in terms of their theoretical basis and the risks associated with their use. Currently, many opinions and suggestions exist regarding the use of MCDA in forestry. It has been claimed that MCDA alone may not be sufficient for use in forest management. On the other hand, hybrid approaches has been reported as suitable for application in this field (Kangas \& Kangas 2005).

Because each mapping expert has different knowledge and experience, traditional management plans can show spatial and temporal differences. To solve the above discrepancies, management plans produced using objective criteria and suitable methods (like GIS) may help to achieve consistency among maps pertaining to different revision periods and/or maps of adjacent planning units.

The main goal of this study is the creation of semi-automated, objective maps based on forest stand volume calculated from ground survey data. To achieve this goal, the spatial analysis capability of GIS was used. The regularized spline with tension (RST) spatial interpolation method was used to produce volume prediction maps of species, and ELECTRE TRI MCDA was applied to create the final forest map needed for objective decision making.

\section{Materials and methods}

\section{Study Area}

The study was conducted in the Asar and the Yenice forest ranges, two managed forest areas located on Mount Ida in Turkey (Fig. 1). The Asar range includes 11159 ha of productive and 2473 ha of non-productive area. In the Yenice range the productive and non-productive areas are 10817 ha and 1816 ha, respectively. The terrain is hilly throughout these forests. Minimum and maximum elevation are $100 \mathrm{~m}$ and $1.000 \mathrm{~m}$ a.s.1., respectively. The primary tree species found are oak species (Quercus sp.), Anatolian black pine (Pinus nigra Arn.), Calabrian pine (Pinus brutia Ten), Oriental beech (Fagus orientalis Lipsky), common hornbeam (Carpinus betulus L.), Trojan fir (Abies nordmanniana (Stev.) Spach. subsp. equi-trojani (Asch. \& Sint. ex Boiss.) Coode \& Cullen), Spanish chestnut (Castanea sativa Mill.) and other deciduous species (e.g., silver lime (Tilia sp.), Alnus glutinosa L. - Anonymous 2011a, 2011b).

Total forest acreage for Turkey in 2004 was 21188747 ha (1 831536 ha of deciduous forests, 11403791 ha of coniferous forests, 2204268 ha of mixed forests and 5749152 ha of coppice (General Directorate of Forests 2006).

The study area is mainly covered by mixed forests, whose structural heterogeneity is known to hinder the application of interpolation methods, thus representing a challenging test for the assessment of the applied methodology in such environments.

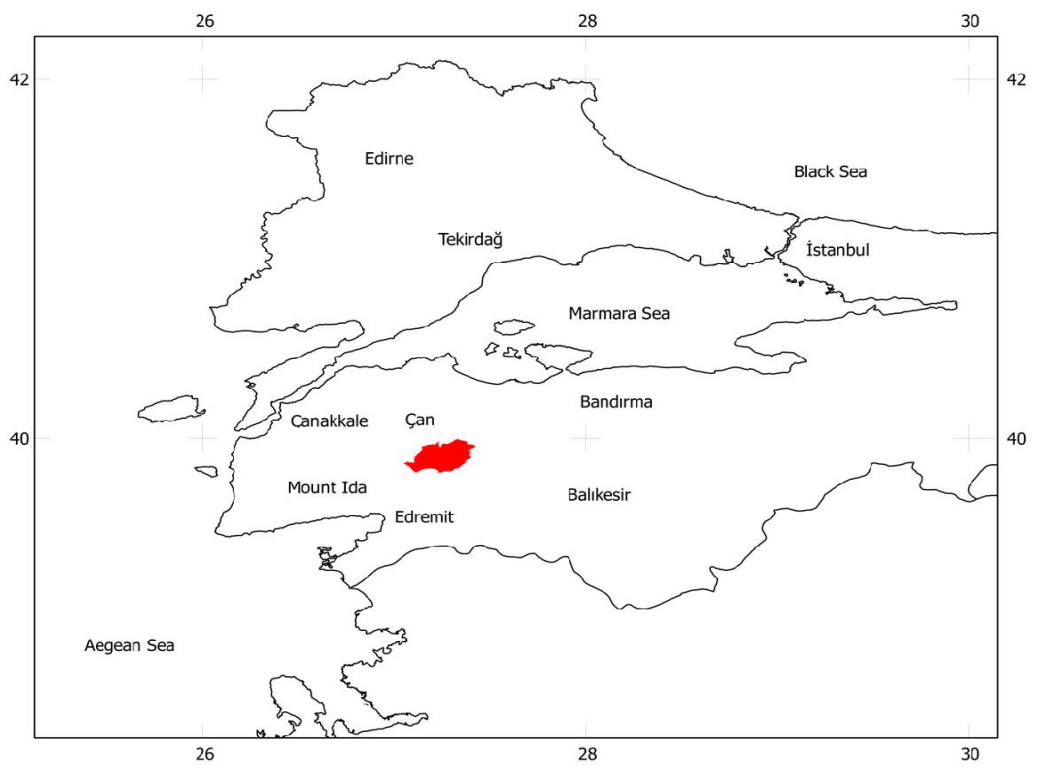

Fig. 1 - The study area. 


\section{Vegetation Data}

The 2010 management year inventory data for the Asar and Yenice forest range were used in this study. The inventory data consisted of 1050 circular sample plots (size: 200, 400, 600, and $800 \mathrm{~m}^{2}$ ) systematically placed at $300 \mathrm{~m}$ intervals. Within each plot, measurements were taken for diameter, mean height, top height, age, health status and stem quality of each tree. The most frequent sampling plot size was chosen to achieve a pixel resolution for the interpolation maps equal to the size of the sample plots of development age $c\left(400 \mathrm{~m}^{2}\right.$ - see below). Due to the inventory method adopted, the forest structure within approximately $50 \mathrm{~m}$ of the center of the sample plot was checked visually. Any distinctive, observable characteristics within the plot and along the path from plot to plot were recorded.

The classification of even-aged stands was performed according to the 2008 Turkish forest management instructions. Diameter ranges were grouped in the following classes: (a) 1.0-7.9 cm; (b) 8.0-19.9 cm; (c) 20.0-35.9 cm; (d) 36.0-51.9 cm; and $(e)>$ $52.0 \mathrm{~cm}$. In diameter class $a$, no measurements were taken for the calculation of stand parameters.

Forest inventory and the production of stand maps in Turkey include the following steps:

1. The management-planning unit is divided into homogeneous segments based on remote sensing images.

2. In the planning units, measurements and determinations are performed in sampling plots distributed according to a systematic sampling scheme.

3 . The sampling plots are grouped by the similarity of tree species and mixture, diameter class, site class, and canopy density.

4. The averages calculated for these groups are taken as representative of the parameters for the whole stand.

5. Each different group is placed within a common stand type.

6. Stand boundaries are defined based on the information recovered from the sampling points located on the stand map.

7. A stand map based on the defined boundaries and features is produced.

The vector and attribute data for the sample plots were entered into the GRASS GIS software database (GRASS Development Team 2011, Tattoni et al. 2010, Neteler et al 2012) in accordance with the methodological steps to produce an objective forest map (Fig. 2). The calculated volumes of tree species per ha were combined with the vector data. Eight different tree species occur in the study area. Of these eight species, the most common are Anatolian black pine, oak species, Oriental beech, and Calabrian pine (Tab. 1). Oak was present in 670 of 1050 plots in the $b$ diameter class, and black pine

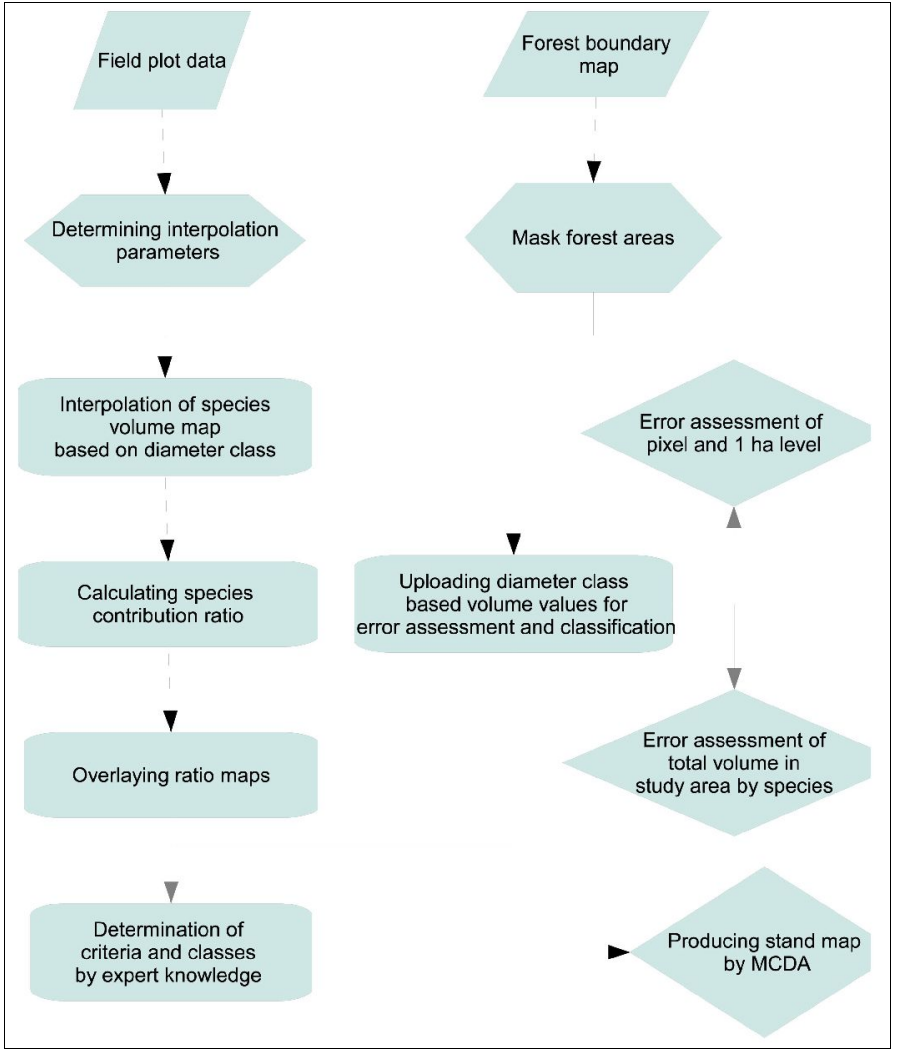

Fig. 2 - Synopsis of the methodological steps carried out in this investigation.

was present in 564 of 1050 plots in the $c$ diameter class. Black pine had the highest mean volume per ha $\left(124.26 \mathrm{~m}^{3} \mathrm{ha}^{-1}\right)$ in the $e$ diameter class, and the maximum volume per ha $\left(549.65 \mathrm{~m}^{3} \mathrm{ha}^{-1}\right.$ - Tab. 1). Based on the data for the presence of species by diameter class in the survey plots, the seven most common species according to diameter class $(\mathrm{Q} b, \mathrm{Pn} c$, $\operatorname{Pn} b, \mathrm{Q} c, \mathrm{Pn} d, \mathrm{Pn} e, \mathrm{Fo} c$ ) were selected to determine the spatial interpolation tension and the smoothing parameters of the RST interpolation method. These seven species and diameter classes were chosen because potential error in the class with the largest volume and number of sample points could potentially influence the entire evaluation.

\section{Determining spatial interpolation para- meters}

To minimize the effects of prediction error and to determine the prediction parameters, different tension and smoothing parameters were tested using the "v.surf.rst" module (spatial approximation and topographic analysis from a given point or isoline data in vector format to floating point raster format using regularized spline with tension) of the GRASS software (GRASS Development Team 2011). The cross-validation and deviation values were calculated for the seven most common species by diameter class.

Cross-validation (Efron \& Gong 1983) was performed by dividing the data into two groups. The first group was used for interpolation using the method under evaluation.
The second group was then used for comparison (Schaffer 1993, Shao 1993). "Leaveone-out" cross-validation is a very common procedure and is frequently implemented in GIS packages. By minimizing the rootmean-square error (RMSE), cross-validation ensures that optimal interpolation parameters are found (Hofierka et al. 2002).

\section{Prediction of forest map}

Spatial interpolation methods transform data representing a continuous phenomenon in a vector point-and-line. This transformation involves mathematical functions allowed to pass through or near given points (Neteler \& Mitasova 2008). Data collected for forest inventories are generally pinpointbased because of the cost associated with the inventories. Pinpoint data are converted into continuous surfaces with the spatial interpolation functions implemented into the GIS package. Although many interpolation methods exist, GRASS software provides the analytic capability needed for methods such as Voronoi polygons, IDW and RSWT (Neteler \& Mitasova 2008).

The changeable approach to intermediary estimation depends on the solution to the following problem: does the intermediary estimation function pass through or close to the data points, or can it be smoothed as much as possible? These two requirements are combined into a single condition to decrease the total deviation at the measured points and to smooth the spline function 
Tab. 1 - Summary statistics for inventory data and error results. (MAE): Mean absolute error; (MAD): Mean absolute error/Mean.

\begin{tabular}{|c|c|c|c|c|c|c|c|c|c|c|}
\hline $\begin{array}{l}\text { Tree } \\
\text { species }\end{array}$ & $\begin{array}{c}\text { Diameter } \\
\text { class }\end{array}$ & $\begin{array}{c}\text { Number } \\
\text { sample } \\
\text { plots }\end{array}$ & Min & $\operatorname{Max}$ & Mean & $\begin{array}{c}\text { Standard } \\
\text { error }\end{array}$ & $\begin{array}{c}\text { MAE } \\
\mathbf{4 0 0} \mathrm{m}^{2}\end{array}$ & $\begin{array}{l}\text { MAD } \\
400 \mathrm{~m}^{2}\end{array}$ & $\begin{array}{c}\text { MAE } \\
1 \text { ha }\end{array}$ & $\begin{array}{r}\text { MAD } \\
1 \text { ha }\end{array}$ \\
\hline Black & $b$ & 555 & 0.28 & 142.43 & 14.5 & 21.09 & 0.37 & 0.03 & 1.65 & 0.11 \\
\hline \multirow[t]{3}{*}{ pine } & $c$ & 564 & 3.16 & 348.4 & 64.14 & 61.03 & 1.61 & 0.03 & 7.55 & 0.12 \\
\hline & $d$ & 463 & 13.03 & 500.85 & 91.88 & 80.55 & 2.56 & 0.03 & 10.31 & 0.11 \\
\hline & $e$ & 299 & 30.56 & 549.65 & 124.26 & 84.84 & 2.54 & 0.02 & 11.07 & 0.09 \\
\hline \multirow{4}{*}{$\begin{array}{l}\text { Calabrian } \\
\text { pine }\end{array}$} & $b$ & 145 & 0.37 & 77.08 & 10.13 & 14.99 & 0.07 & 0.01 & 0.35 & 0.03 \\
\hline & $c$ & 167 & 2.31 & 208.8 & 43.11 & 39.01 & 0.29 & 0.01 & 1.5 & 0.03 \\
\hline & $d$ & 131 & 1.3 & 373.28 & 79.04 & 67.08 & 0.51 & 0.01 & 2.47 & 0.03 \\
\hline & $e$ & 75 & 25.31 & 413.68 & 101.83 & 79.41 & 0.35 & 0 & 1.84 & 0.02 \\
\hline \multirow{4}{*}{$\begin{array}{l}\text { Other } \\
\text { deciduous }\end{array}$} & $b$ & 166 & 0.44 & 23.63 & 4.94 & 4.74 & 0.06 & 0.01 & 0.3 & 0.06 \\
\hline & $c$ & 49 & 3.06 & 51.1 & 11.29 & 9.96 & 0.05 & 0 & 0.24 & 0.02 \\
\hline & $d$ & 3 & 22 & 29.42 & 25.71 & 5.25 & 0 & 0 & 0.02 & 0 \\
\hline & $e$ & 2 & 34 & 34 & 34 & 0 & 0 & 0 & 0.02 & 0 \\
\hline \multirow{4}{*}{$\begin{array}{l}\text { Kazdagi } \\
\text { fir }\end{array}$} & $b$ & 60 & 0.4 & 31.1 & 8.06 & 7.27 & 0.03 & 0 & 0.16 & 0.02 \\
\hline & $c$ & 54 & 4.47 & 114.9 & 28.36 & 25.9 & 0.11 & 0 & 0.51 & 0.02 \\
\hline & $d$ & 29 & 22.73 & 191.53 & 63.73 & 41.75 & 0.14 & 0 & 0.67 & 0.01 \\
\hline & $e$ & 10 & 30.34 & 105.33 & 56.95 & 24.62 & 0.05 & 0 & 0.25 & 0 \\
\hline Horn & $b$ & 12 & 0.58 & 27.63 & 9.38 & 9.8 & 0.01 & 0 & 0.05 & 0.01 \\
\hline \multirow{2}{*}{ Beam } & $c$ & 6 & 4.5 & 34.83 & 17.41 & 11.5 & 0.01 & 0 & 0.04 & 0 \\
\hline & $d$ & 3 & 18 & 27 & 22.5 & 6.36 & 0 & 0 & 0.02 & 0 \\
\hline \multirow{4}{*}{$\begin{array}{l}\text { Oriental } \\
\text { beech }\end{array}$} & $b$ & 202 & 0.47 & 44.93 & 11.69 & 9.83 & 0.13 & 0.01 & 0.53 & 0.05 \\
\hline & $c$ & 179 & 3.88 & 202.78 & 54.29 & 41.53 & 0.68 & 0.01 & 2.2 & 0.04 \\
\hline & $d$ & 98 & 14.4 & 360.27 & 60.56 & 51.64 & 0.48 & 0.01 & 1.74 & 0.03 \\
\hline & $e$ & 36 & 29.7 & 338.8 & 92.37 & 70.37 & 0.37 & 0 & 1.33 & 0.01 \\
\hline \multirow{4}{*}{$\begin{array}{l}\text { Spanish } \\
\text { chestnut }\end{array}$} & $b$ & 31 & 0.6 & 19.3 & 5.53 & 4.17 & 0.02 & 0 & 0.08 & 0.01 \\
\hline & $c$ & 25 & 6.3 & 103.6 & 23.48 & 22.27 & 0.06 & 0 & 0.27 & 0.01 \\
\hline & $d$ & 7 & 17.63 & 60.1 & 37.33 & 14.3 & 0.02 & 0 & 0.11 & 0 \\
\hline & $e$ & 5 & 17.77 & 136.6 & 74.61 & 51.2 & 0.02 & 0 & 0.13 & 0 \\
\hline \multirow[t]{4}{*}{ Oaks sp. } & $b$ & 670 & 0.44 & 70.85 & 11.89 & 11.35 & 0.35 & 0.03 & 1.61 & 0.14 \\
\hline & $c$ & 514 & 2.71 & 148.75 & 30.55 & 25.19 & 0.72 & 0.02 & 3.2 & 0.10 \\
\hline & $d$ & 289 & 8.73 & 173.85 & 43.62 & 31.53 & 0.75 & 0.02 & 3.39 & 0.08 \\
\hline & $e$ & 158 & 17.85 & 240.25 & 65.46 & 45.29 & 0.71 & 0.01 & 3.43 & 0.05 \\
\hline
\end{tabular}

semi-norm (Mitasova et al. 1995, Mitas \& the inventory sampling plots in the field Mitasova 1999). Splines including the selection of the covariance function, as specified by numerous authors, are equivalent to universal kriging (Hengl 2007, Neteler \& Mitasova 2008).

Predictions based on the volume values per ha were obtained with the estimation parameters determined from the cross-validation and deviation method. This procedure (RST) is implemented within GRASS's "v.surf.rst" module (GRASS Development Team 2011). Subsequently, the maps obtained were processed with particular GIS commands to produce the species contribution ratio maps and the mixture map.

\section{Error assessment}

The accuracy of the prediction maps computed with RST was calculated on both point and area basis. The MAE (Mean Absolute Error) and the MAD (Mean Absolute Deviation) were determined during the evaluation of the errors in the volume-estimation maps. The "v.sample" command was used to determine the point-wise error, and the "v.rast.stats" command was used to determine the area-wise error. The volumes (in ha) derived from the measured values from were compared with the predicted values at the applicable point on the maps obtained by interpolation. The area-based evaluation considered that each sample point represented precisely 1 ha. In addition, the total areabased volume was calculated and compared with the value obtained from conventional inventory methods.

\section{Production of stand map from interpo- lation maps}

The computed raster maps of the volume per ha for each species $(\mathrm{Pb}, \mathrm{Pn}, \mathrm{Ab}, \mathrm{Fo}, \mathrm{Q}$, $\mathrm{Cb}, \mathrm{Cs}$, Od) were converted to vector maps and then overlaid to produce a vector map displaying the mixture ratios of the 8 species. The combinations acquired from these maps were evaluated with expert knowledge of forest management. This evaluation was then used to determine the criteria and classes for making the final decision map for the managed forest. For example, in Tab. 2, 8 species and diameter class combinations were categorized into a single category by defined expert knowledge criteria. All other similar combinations were categorized with this approach. This procedure used the ELECTRE TRI "Bouyssou-Marchant" mo- del in Quantum GIS (Quantum GIS Development Team 2012, Sobrie 2010).

\section{Results}

Determining spatial interpolation parameters

Based on the cross-validation results obtained in this study, the interpolation parameters showing the lowest RMSE value varied among the seven diameter classes considered (Tab. 3). Therefore, a map showing the deviation of the seven most common species by diameter class was calculated. All diameter classes gave the minimum mean absolute-deviation error, with a value of 80 for the tension parameter and a value of 0.2 for

Tab. 2 - ELECTRE TRI categorization sample.
1. 6Pn2Fo1Q1Cb de
2. $6 \mathrm{Pn} 2 \mathrm{Fo} 1 \mathrm{Q} 1 \mathrm{Cb} \mathrm{de}$
3. $6 \mathrm{Pn} 3 \mathrm{Fo} 1 \mathrm{Q}$ de
4. $6 \mathrm{Pn} 2 \mathrm{Fo} 2 \mathrm{Q}$ de
5. $6 \mathrm{Pn} 2 \mathrm{Fo} 2 \mathrm{Q}$ ed
6. $6 \mathrm{Pn} 2 \mathrm{Fo} 1 \mathrm{Q} 1 \mathrm{Cb}$ ed
7. $6 \mathrm{Pn} 1 \mathrm{Fo} 2 \mathrm{Q} 1 \mathrm{Cb} \mathrm{d}$
8. $6 \mathrm{Pn} 2 \mathrm{Fo} 2 \mathrm{Cb} \mathrm{de}$ 
the smoothing parameter (Tab. 3). The use of these values for interpolation would likely decrease the error rate.

\section{Prediction of forest maps}

A total of 31 independent interpolation maps were obtained for the diameter classes of each species (e.g., black pine in Fig. 3a, b, $\mathrm{c}$, and $\mathrm{d}$ ). The total volumes of particular species per ha (e.g., black pine: $\operatorname{Pn} b+\operatorname{Pn} c+$ $\left.\mathrm{Pn} d+\mathrm{Pn} e=\mathrm{Pn}_{\mathrm{t}}\right)$ were computed by summing these species-diameter-class interpolation maps (Fig. 4a). The percentage contributions of each diameter class to the mixture were obtained by calculating the ratios of the diameter class volume of the particular species and the total volume of the species (e.g., $\mathrm{Pn} b / \mathrm{Pn}_{\mathrm{t}}$ ) with the help of this map (Fig. 4b). Similarly, the summation of the total volumes of each species per ha $\left(\mathrm{Pn}_{\mathrm{t}}+\mathrm{Pb}_{\mathrm{t}}+\mathrm{Od}_{\mathrm{t}}+\right.$ $\mathrm{Ab}_{\mathrm{t}}+\mathrm{Cb}_{\mathrm{t}}+\mathrm{Fo}_{\mathrm{t}}+\mathrm{Cs}_{\mathrm{t}}+\mathrm{Q}_{\mathrm{t}}=\mathrm{V}_{\mathrm{t}}$ ) yielded the total volume per ha of the trees in the planning units (Fig. 4c). The percentage contributions of each species to the mixture were obtained by calculating the ratios of the total volume of the species and the overall total volume $\left(\right.$ e.g., $\left.\mathrm{Pn}_{\mathrm{t}} / \mathrm{V}_{\mathrm{t}}\right)$ with the help of this map (Fig. 4d)

\section{Error assessment of predictions}

If the predictions were evaluated on the basis of the size of one pixel $\left(400 \mathrm{~m}^{2}\right)$, the results were very satisfactory $(\mathrm{MAD}<4 \%)$. However, on the basis of a sample plot that was approximately one ha in area, the maximum MAD increased to $12 \%(\operatorname{Pn} b)$ and $14 \%(\mathrm{Q} b)$. The maximum standard deviations for the black-pine diameter classes $d$

Tab. 3 - Deviation values for the seven most common species by diameter class.

\begin{tabular}{llllllllll}
\hline Tree & \multicolumn{3}{c}{ Cross validation } & \multicolumn{7}{c}{ Deviation } & Smoothing \\
\cline { 2 - 9 } Species & $\mathbf{2 0}$ & $\mathbf{4 0}$ & $\mathbf{6 0}$ & $\mathbf{8 0}$ & $\mathbf{2 0}$ & $\mathbf{4 0}$ & $\mathbf{6 0}$ & $\mathbf{8 0}$ & \\
\hline Pn $b$ & 6.64 & 6.6 & 6.6 & 6.6 & 0.39 & 0.26 & 0.22 & 0.2 & 0.2 \\
& 6.63 & 6.6 & 6.6 & 6.6 & 0.72 & 0.49 & 0.42 & 0.38 & 0.4 \\
& 6.62 & 6.6 & 6.6 & 6.6 & 1 & 0.71 & 0.61 & 0.55 & 0.6 \\
& 6.61 & 6.6 & 6.61 & 6.61 & 1.26 & 0.91 & 0.78 & 0.72 & 0.8 \\
\hline Pnc & 30.36 & 30.29 & 30.35 & 30.4 & 1.83 & 1.23 & 1.04 & 0.93 & 0.2 \\
& 30.32 & 30.3 & 30.36 & 30.42 & 3.36 & 2.32 & 1.98 & 1.79 & 0.4 \\
& 30.29 & 30.31 & 30.38 & 30.44 & 4.69 & 3.32 & 2.85 & 2.59 & 0.6 \\
& 30.28 & 30.33 & 30.4 & 30.46 & 5.87 & 4.23 & 3.66 & 3.35 & 0.8 \\
\hline Pnd & 39.66 & 39.4 & 39.37 & 39.37 & 2.38 & 1.59 & 1.34 & 1.2 & 0.2 \\
& 39.58 & 39.38 & 39.36 & 39.37 & 4.38 & 3 & 2.55 & 2.31 & 0.4 \\
& 39.52 & 39.37 & 39.36 & 39.38 & 6.12 & 4.3 & 3.68 & 3.35 & 0.6 \\
& 39.47 & 39.36 & 39.36 & 39.39 & 7.65 & 5.49 & 4.73 & 4.32 & 0.8 \\
\hline Pne & 43.38 & 42.92 & 42.84 & 42.82 & 2.73 & 1.8 & 1.51 & 1.35 & 0.2 \\
& 43.23 & 42.88 & 42.83 & 42.81 & 4.98 & 3.38 & 2.86 & 2.58 & 0.4 \\
& 43.13 & 42.86 & 42.81 & 42.8 & 6.92 & 4.82 & 4.11 & 3.73 & 0.6 \\
& 43.05 & 42.84 & 42.8 & 42.79 & 8.63 & 6.14 & 5.27 & 4.8 & 0.8 \\
\hline Foc & 8.5 & 8.49 & 8.53 & 8.57 & 0.53 & 0.35 & 0.29 & 0.27 & 0.2 \\
& 8.48 & 8.5 & 8.55 & 8.58 & 0.98 & 0.67 & 0.57 & 0.51 & 0.4 \\
& 8.47 & 8.51 & 8.56 & 8.59 & 1.37 & 0.96 & 0.82 & 0.75 & 0.6 \\
& 8.46 & 8.52 & 8.57 & 8.61 & 1.71 & 1.22 & 1.06 & 0.97 & 0.8 \\
\hline Q $b$ & 6.5 & 6.42 & 6.41 & 6.4 & 0.4 & 0.26 & 0.22 & 0.2 & 0.2 \\
& 6.47 & 6.41 & 6.4 & 6.4 & 0.73 & 0.5 & 0.42 & 0.38 & 0.4 \\
& 6.46 & 6.41 & 6.4 & 6.4 & 1.01 & 0.71 & 0.61 & 0.55 & 0.6 \\
& 6.44 & 6.41 & 6.4 & 6.41 & 1.26 & 0.9 & 0.78 & 0.71 & 0.8 \\
\hline Q $c$ & - & - & - & - & 0.78 & 0.52 & 0.43 & 0.39 & 0.2 \\
& - & - & - & - & 1.44 & 0.98 & 0.83 & 0.75 & 0.4 \\
& - & - & - & - & 2 & 1.4 & 1.2 & 1.09 & 0.6 \\
& - & - & - & - & 2.5 & 1.78 & 1.54 & 1.4 & 0.8 \\
\hline & & & & & & & & &
\end{tabular}

and $e$, were $81 \%$ and $85 \%$, respectively (Tab. 1). High standard deviations were also found for the Calabrian-pine diameter classes $d$ and $e$ (67\% and 79\%, respectively),
Oriental beech (51\% and 70\%, respectively), and oak spp. (31\% and $45 \%$, respectively).

The total volume by species as determined by conventional methods (Forest Manage-
Fig. 3 - Interpolation maps of black pine. (A) diameter class $b$; (B) diameter class $c$; (C) diameter class $d$; (D) diameter class $e$.

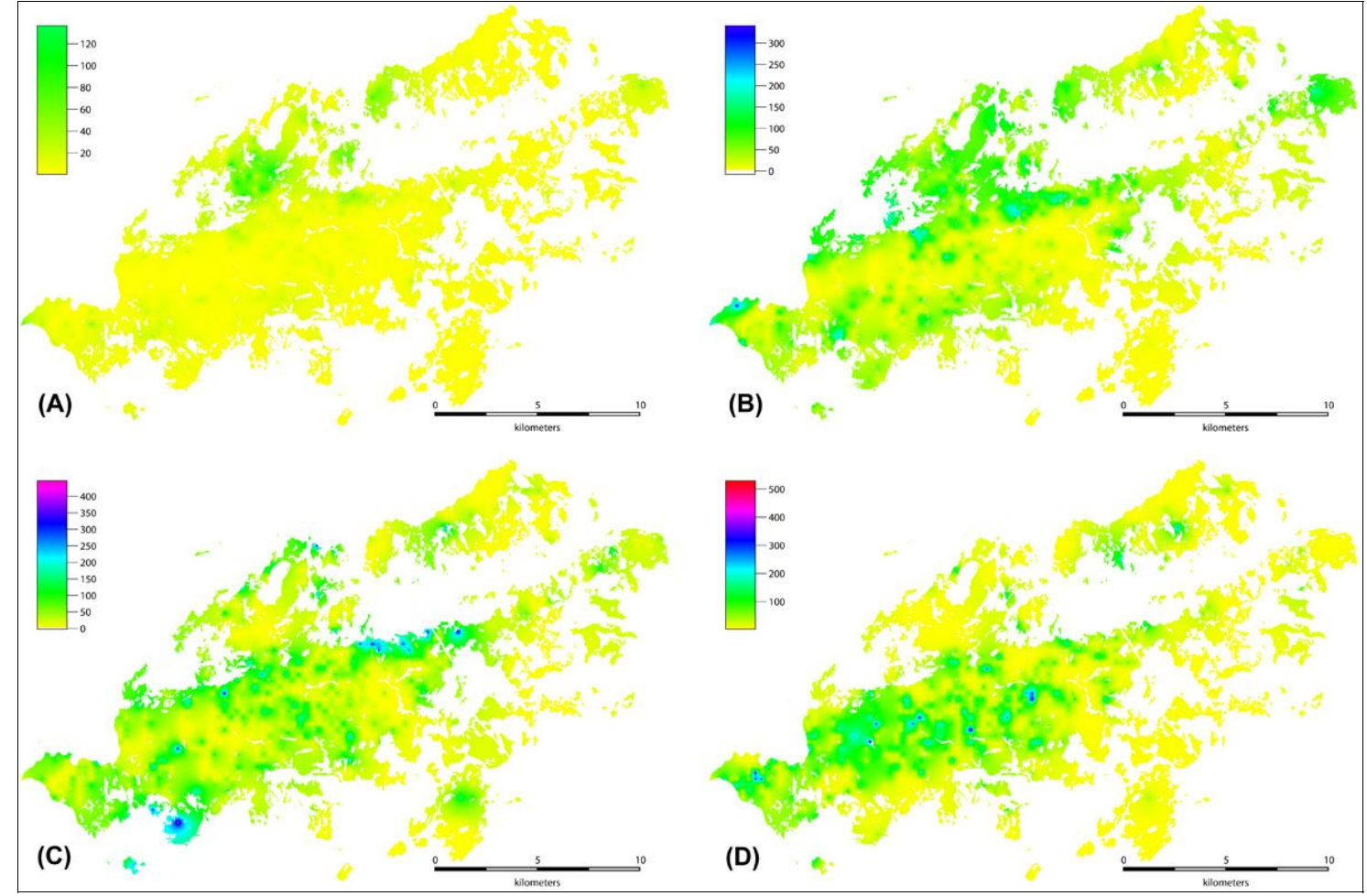




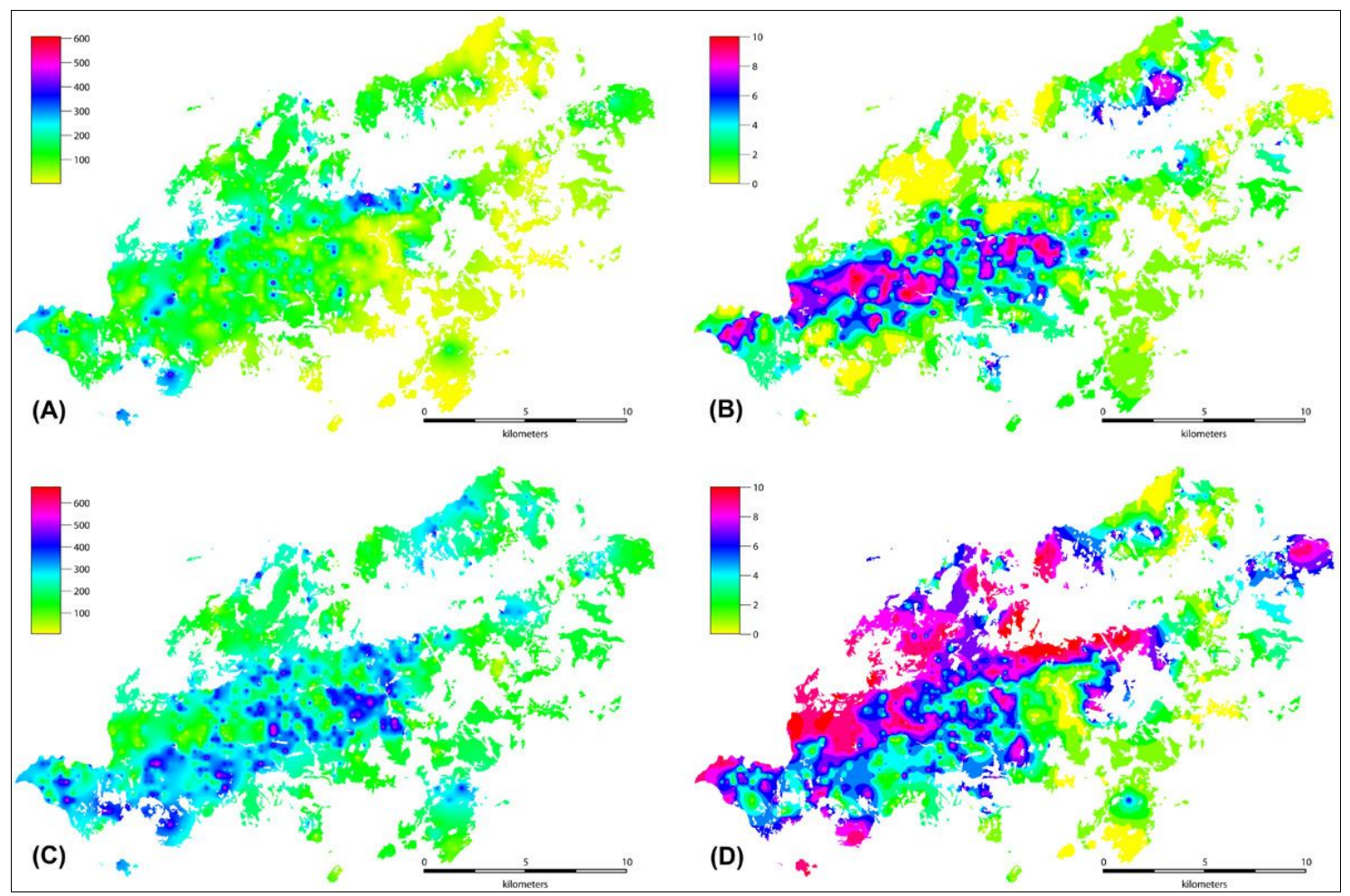

Fig. 4 - (A) Total volume map for black pine; (B) volume ratio map for black pine (diameter class $b$ ); (C) total volume map for all the species; (D) volume ratio map for black pine.

ment Regulation Handbook 2008) and was compared to that determined by the methods applied in our study for the entire study area (Tab. 4). The data over the entire area showed that four species had volume ratios greater than $1 \%$. In descending order of

volume ratios, these species were $\mathrm{Pn}>\mathrm{Q}>$ $\mathrm{Pb}>\mathrm{Fo}$, with volume ratio values of $55 \%$, $19 \%, 16 \%$, and $8 \%$, respectively. These four species represented a total volume of $98 \%$. The maximum relative errors were calculated for the Calabrian pine diameter classes $b$ and

Tab. 4 - Accuracy of total volume calculated with spatial interpolation (SI), compared with conventional forest inventory results (CFIR). Total volume contribution percent in study area.

\begin{tabular}{|c|c|c|c|c|c|c|c|}
\hline \multirow{2}{*}{$\begin{array}{l}\text { Tree } \\
\text { species }\end{array}$} & \multirow{2}{*}{$\begin{array}{l}\text { Type of } \\
\text { estimation }\end{array}$} & \multicolumn{4}{|c|}{ Diameter } & \multirow{2}{*}{$\begin{array}{c}\text { Total } \\
\text { contribution }\end{array}$} & \multirow{2}{*}{$\begin{array}{c}\text { Total } \\
\text { partecipant }\end{array}$} \\
\hline & & Class $b$ & Class $c$ & Class $d$ & Class $e$ & & \\
\hline \multirow[t]{3}{*}{$\mathrm{Pb}$} & SI & 36226 & 165430 & 248434 & 220339 & 670428 & 0.16 \\
\hline & CFIR & 27332 & 134388 & 211765 & 180807 & 554292 & \\
\hline & $\%$ & 33 & 23 & 17 & 22 & 21 & \\
\hline \multirow[t]{3}{*}{$\mathrm{Pn}$} & SI & 146309 & 611316 & 695638 & 559590 & 2012853 & 0.55 \\
\hline & CFIR & 160647 & 529222 & 614516 & 625805 & 1930190 & \\
\hline & $\%$ & -9 & 16 & 13 & -11 & 4 & \\
\hline \multirow[t]{3}{*}{$\mathrm{Ab}$} & SI & 5507 & 15973 & 20363 & 5326 & 47169 & 0.01 \\
\hline & CFIR & 4273 & 12838 & 16481 & 6034 & 39626 & \\
\hline & $\%$ & 29 & 24 & 24 & -12 & 19 & \\
\hline \multirow[t]{3}{*}{ Fo } & SI & 34856 & 141304 & 95689 & 52129 & 323978 & 0.08 \\
\hline & CFIR & 31873 & 128509 & 80135 & 44008 & 284525 & \\
\hline & $\%$ & 9 & 10 & 19 & 18 & 14 & \\
\hline \multirow[t]{3}{*}{ Q } & SI & 132299 & 233543 & 176357 & 150154 & 692353 & 0.19 \\
\hline & CFIR & 132519 & 228881 & 170362 & 147514 & 679276 & \\
\hline & $\%$ & 0 & 2 & 4 & 2 & 2 & \\
\hline \multirow[t]{3}{*}{$\mathrm{Cb}$} & SI & 1111 & 1023 & 710 & 0 & 2845 & 0 \\
\hline & CFIR & 1101 & 871 & 576 & 0 & 2548 & \\
\hline & $\%$ & 1 & 17 & 23 & - & 12 & \\
\hline \multirow[t]{3}{*}{$\mathrm{Cs}$} & SI & 2367 & 7859 & 3324 & 4979 & 18529 & 0 \\
\hline & CFIR & 2092 & 7351 & 2759 & 2035 & 14237 & \\
\hline & $\%$ & 13 & 7 & 20 & 145 & 30 & \\
\hline \multirow[t]{3}{*}{ Od } & SI & 13044 & 9291 & 1333 & 785 & 24452 & 0.01 \\
\hline & CFIR & 12228 & 7363 & 2414 & 257 & 22262 & \\
\hline & $\%$ & 7 & 26 & -45 & 205 & 10 & \\
\hline
\end{tabular}

c. These relative error values were $+33 \%$ and $+23 \%$, respectively. The minimum relative errors for these four species were calculated for diameter classes $b, c$, and $d$ of the oak species. These relative error values were $2 \%$, $4 \%$, and $2 \%$, respectively.

Black pine had a maximum volume ratio of $55 \%$ for the entire study area and a total relative error of $4 \%$. The relative error rates for the individual diameter classes were $16 \%$ for class $c, 13 \%$ for class $d$ and $-11 \%$ for class $e$. Oriental beech has the lowest volume ratio $(8 \%)$ of the four highest-volume species. The relative error for the total volume was $14 \%$. The relative errors for the diameter classes were $10 \%, 19 \%$, and $18 \%$ for classes $c, d$, and $e$, respectively.

Generally, the highest relative errors in volume estimation occurred for diameter classes $c$ and $d$.

The pixel-based (sampling area-based) MAE and the area-based MAE followed similar trends. The pixel-based MAD values ranged between $0 \%$ and $3 \%$.

When producing the forest stand map from the interpolation maps, the diameter class for each value of species volume derived from the raster maps was uploaded with the "v.rast.stats" command onto the vector map as attribute data. The resulting species mixtures, including both volume-based dominants and accompanying secondary species, were then considered. In the next stage of the process, the 890 different mixture variations were reduced to a smaller number of categories based on expert knowledge. Criteria were established based on the mixture 
Fig. 5 - Stand type maps obtained using the ELECTRE TRI approach by combining the 31 prediction maps of the volume per ha.

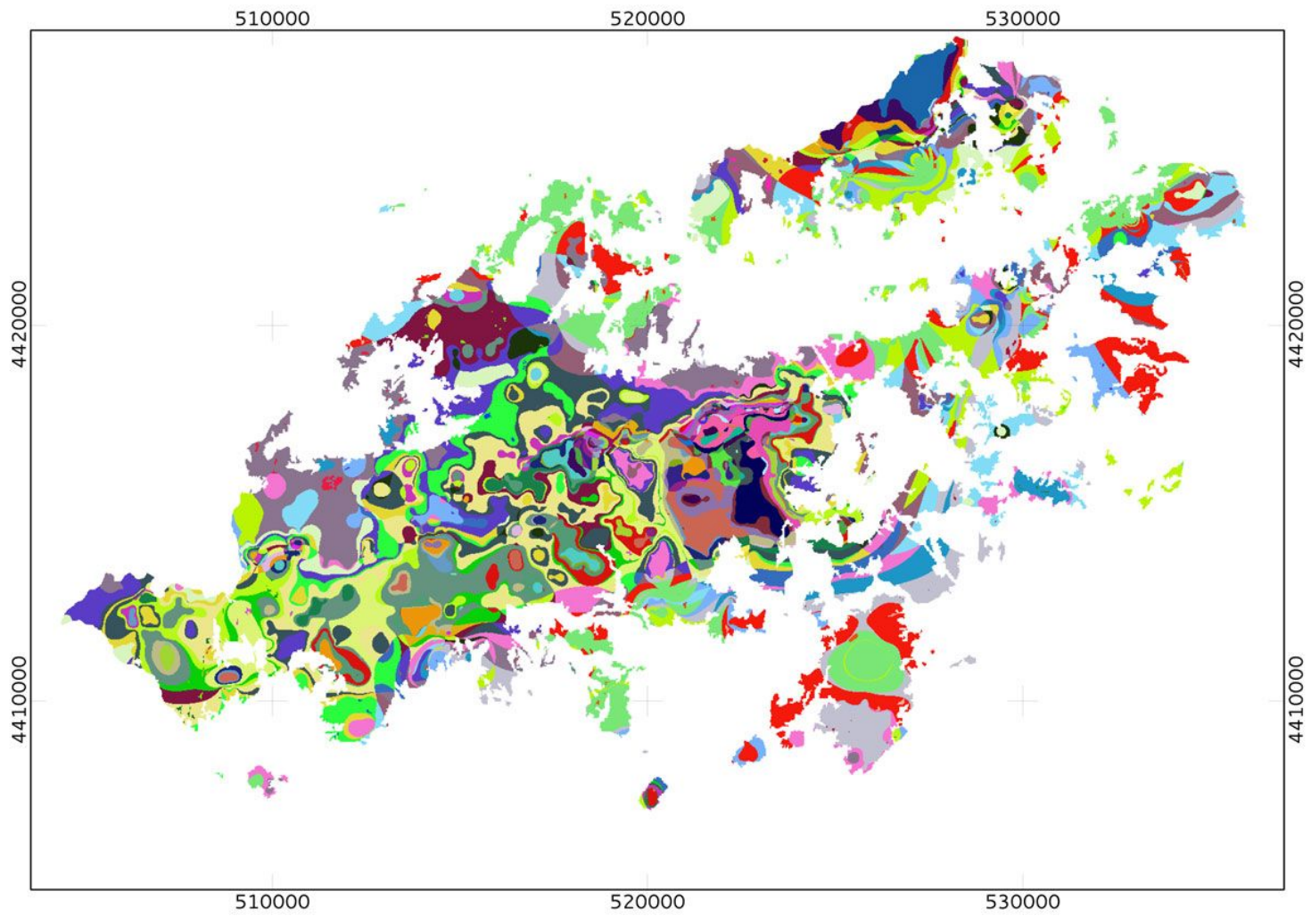

rates of the tree species and the average volumes for the diameter classes. These ELECTRE TRI criteria and the values for the weights were then entered, and 70 different profiles were generated. The ELECTRE TRI module of QGIS was used to create a final decision map. This map represents 70 different profile categories based on species mixture rates and diameter classes (Fig. 5).

\section{Discussion}

Diameter classes $d$ and $e$ showed the larger standard devistions for species representing $98 \%$ of the total volume (Tab. 1). In general, the observed error values were as low as expected from the associated standard deviations, with occasional exceptions. Minor differences were found between MAD errors at the pixel level and at the 1-ha level.

The observed differences in MAE among diameter classes for the same species could be interpreted as due to variation in site index between neighboring plots, that could cause the volume to increase by approximately $15 \%$. Moreover, differences in canopy closure between neighboring stands could have also contributed to the observed differences in MAE described above. Therefore, MAE could be reduced by including the above parameters in the volume estimation, although the number of maps to be produced would also increase.

In the species diameter class with approximately 300 observations distributed around a value of about 300 , the MAD values calculated on the basis of 1 ha were $8 \%$ and $9 \%$ for $\mathrm{Q} d$ and Pne, respectively. Increasing the number of species found at the sampling points ( $\mathrm{Q} b, \operatorname{Pn} c, \operatorname{Pn} b, \operatorname{Pn} d$, and $\mathrm{Q} c)$, the same trend was observed. This increase in the error values is not affected by standard deviation or mean volume (Tab. 1). These maximum MAD values could result from the distribution of black pine and oak species in the study area. Indeed, data heterogeneity may fairly affect the performance of the methods (Li \& Heap 2011).

The design of the RST method adopted in this study ensures that the predicted values at a given points remain very close to the observed values at that point. Thus, the MAD of the sampling plots $\left(400 \mathrm{~m}^{2}=1\right.$ pixel $)$ did not increase at the ha level $\left(10000 \mathrm{~m}^{2} / 400\right.$ $\mathrm{m}^{2}=25$ pixels). This result reflects the characteristics of the inventoried sample plots, whose structure was fairly similar to the forest structure in the surrounding area.

The volumes obtained by the RST method were slightly higher than the corresponding values in the forest management plan data (Tab. 4). Black pine showed the highest volume ratio $(55 \%)$, with a relative error of $4 \%$ only. The largest error value was detected for diameter class $b$ of Calabrian pine. The observed differences can be accounted for by differences between the two methods. The classical method adopted in forest management plans evaluates the data groups separately to create separate stand types. Instead, the spatial interpolation approach used here evaluates the data relative to the overall configuration of the observations and the spatial scales. Different results are also expected because of the subjective personal evaluations involved in conventional approaches.

According to the 2008 Turkish Forest Management Regulation Handbook (2008), an error $\leq 10 \%$ in volume assessment would be expected for production forests. However, unlike production forests, an error rate $>$ $10 \%$ is accepted for protected forests because each systematic sampling point is 600 x $600 \mathrm{~m}=36000 \mathrm{~m}^{2}$. Thus, based on the above criteria, the results of this study could be considered as acceptable.

In this study, a final decision map has been produced representing 70 different profile categories based on species mixture rates and diameter classes in the area analyzed (Fig. 5), obtained combining the prediction maps produced. The method adopted has facilitated the reductions performed for adjacent diameter classes. In addition, the small forest fragments were integrated into a general framework by the analysis. Therefore, this approach facilitated the reduction of small fragments until the structural and statistical features of the desired stand types were attained, in accordance with management goals. To perform this reduction process in a objective way, the ELECTRE TRI method was used. Aktas \& Yilmaz (2011) also used the same methodology to produce a stand map from interpolation maps. The above process would require the use of expert knowledge on forest management to make an improved decision map.

The area considered in this study enlarged 
upon both forested and non-forested zones (e.g., agricultural areas, settlements, and grasslands). To avoid the effect of the latter areas on total volume assessment, adequate masks were used to exclude non-forested area from the analysis. An additional problem encountered is the accuracy of predictions near the boundaries of the forest management units. The incorporation of neighboring plan units in these areas is an appropriate way of improving the accuracy of predictions. Nevertheless, the resulting map should be refined through aerial photography or satellite images.

Spatial interpolation methods (especially kringing) have been previously argued as unsuitable for assessment purposes in managed forests (Akhavan et al. 2010). On the other hand, several studies have reported successful application of such methods in homogenous natural forest areas (Gunnarsson et al 1998, Tuominen et al. 2003).

The RST method adopted here allows the user to create stand maps very efficiently. In order to test the accuracy of volume predictions, cross-validation and resampling methods have been applied (Nanos et al. 2004 Zawadzki et al. 2005, Palmer et al. 2009, Tang \& Bian 2009, Kovacs et al. 2011, Tattoni et al. 2011, Viana et al. 2012), aimed at comparing the observed value at a given point with its prediction obtained from the interpolated continuous surface. However, in areas characterized by highly heterogeneous forest structures, the above approach may not be adequate, and additional control points in the field may be required. On the contrary, a subset of sampling points may be used in areas densely sampled for the above comparisons, keeping the points excluded from analysis for control purposes.

Further improvement of the map obtained may be achieved by the inclusion of auxiliary data (e.g., soil, climate, topography etc.) and the use of multivariate interpolation methods or mixed models, thus combining the most important parameters of the forest stands. For example, several environmental parameters have been used to model the spatial variability in Pinus radiata productivity in New Zealand (Kirschbaum \& Watt 2011). Moreover, remote sensing data may be incorporated into the analysis to obtain an improved accuracy of predictions. Dubayah et al. (2000) found that the LiDAR remote sensing has a vast potential for the direct estimation of several key forest characteristics, such as canopy heights, stand volume, basal area and aboveground biomass (Dubayah \& Drake 2000). Lovell et al. (2005) have performed studies on optimal LiDAR acquisition parameters for forest height retrieval. Estornell et al. (2011) have made estimations of shrub biomass by airborne LiDAR in small forest stands, obtaining accurate measures of the most important plant parameters (volume, average height, diameter and canopy) with minimal costs. Haywood (2011) adopted a semi-automated stand delineation process in the mapping of natural eucalypt forests using remote sensing, multi-spectral imagery, lasers and stand characteristics. Furthermore, the application of LiDAR allows the creation of accurate three-dimensional relief models of forest stands. For example, Mitasova et al. (2005) used a simultaneous spline approximation and topographic analysis for LiDAR elevation data in open-source GIS to create accurate relief models. LiDAR, in combination with inventory data, has also been used to evaluate the forest habitats of birds and other wildlife (Graf et al. 2009, Tattoni et al. 2012, Wilsey et al. 2012, Smart et al. 2012).

Forest management activities depends on international, national, and regional forestry strategies. Moreover, regional planning should include community participation and the analysis of multiple functions of forest resources (Perez-Soba et al. 2006). For this reason, multi-function criteria are often used in forest planning in addition to conventional management criteria, and MCDA has been carried out in different decision-making contexts in forestry. Khadka \& Vacik (2012) used multi-criteria analysis to support community forest management including 6 criteria and 40 profiles. Huth et al. (2005) used multi-criteria analysis to support decisions on harvest volume based on the criteria of rotation, harvest intensity, and target diameter.

In many forestry studies, MCDA was applied using multiple criteria for the assessment of a single parameter (e.g., total volume, site class). Similarily, the MCDA map obtained in our study has also multiple criteria and allows the evaluation of multiple functions. The conventional methods used in Turkey require professional experience and a background of appropriate knowledge. The use of an MCDA method, such as the ELECTRE TRI adopted here, may bypass the above problem.

\section{References}

Akhavan R, Amiri GhZ, Zobeiri M (2010). Spatial variability of forest growing stock using geostatistics in the Caspian region of Iran. Caspian Journal Environmental Sciences 8: 43-53. [online] URL: http://research.guilan.ac.ir/cjes/.papers/1595.pdf

Aktas S, Yilmaz OY (2011). Producing of stand draft maps with spatial prediction methods. Journal of the Faculty of Forestry, Istanbul University, Turkey 62(2):131-146.

Anonymous (2011a). Forest Management Plan Forestry Asar 2010-2019. Regional Directorate of Forests in Çanakkale, General Directorate of Forests, Ministry of Environment and Forests, Ankara, Turkey.

Anonymous (2011b). Forest Management Plan
Forestry Yenice 2010-2019. Regional Directorate of Forests in Canakkale, General Directorate of Forests, Ministry of Environment and Forests, Ankara, Turkey.

Aurbi P, Debouzie D (2000). Geostatistical estimation variance for the spatial mean in two dimensional systematic sampling. Ecology 81: 543-553. - doi: 10.1890/0012-9658(2000)081 [0543:GEVFTS]2.0.CO;2

Balteiro LD, Romero C (2008). Making forestry decisions with multiple criteria: a review and an assessment. Forest Ecology and Management 255: 3222-3241. - doi: 10.1016/j.foreco.2008.01. 038

Burrough PA (2001). GIS and geostatistics: essential partners for spatial analysis. Environmental and Ecological Statistics 8: 361-377. - doi: 10. 1023/A:1012734519752

Dubayah RO, Drake JB (2000). Lidar remote sensing for forestry applications. Journal of Forestry 98 (6): 44-52.

Dubayah R, Knox R, Hofton M, Blair JB, Drake J (2000). Land surface characterization using Lidar remote sensing. In: "Spatial information for land use management" (Hill MJ, Aspinall RJ eds). International Publishers Direct, Singapore, pp. 25-38.

D'Orazio M (2003). Estimating the variance of the sample mean in two-dimensional systematic sampling. Journal of Agricultural, Biological and Environmental Statistics 8: 280-295. - doi: 10.1198/1085711032174

Efron B, Gong G (1983). A leisurely look at the bootstrap, the jackknife, and cross-validation. The American Statistician 37: 36-48. - doi 10.1080/00031305.1983.10483087

Estornell J, Ruiz LA, Velázquez-Martí B, Fernández-Sarría A (2011). Estimation of shrub biomass by airborne LiDAR data in small forest stands. Forest Ecology and Management 262: 1697-1703. - doi: 10.1016/j.foreco.2011.07.026 Feng Y, Tang S, Li Z (2006). Application of improved sequential indicator simulation to spatial distribution of forest types. Forest Ecology and Management 222: 391-398. - doi: 10.1016/j.foreco.2005.10.045

Flores LA, Martinez L I, Ferrer CM (2003). Systematic sample design for the estimation of spatial means. Environmetrics 14: 45-61. - doi: 10.1002/env.564

Forest Management Regulation Handbook (2008). General Directorate of Forests, Ministry of Environment and Forests in Turkey. Official Gazette of the Republic of Turkey No: 26778, pp. 18.

General Directorate of Forests (2006). Forests in Turkey. Ministry of Environment and Forests in Turkey, Ankara, pp. 160.

Graf RF, Mathys L, Bollmann K (2009). Habitat assessment for forest dwelling species using LiDAR remote sensing: Capercaillie in the Alps. Forest Ecology and Management 257: 160-167. doi: 10.1016/j.foreco.2008.08.021

GRASS Development Team (2011). Geographic resources analysis support system (GRASS) Software. Open Source Geospatial Foundation 
Project. [online] URL: http://grass.osgeo.org Guibal D (1973). Estimating oukoumés Gabon. Internal Memo \#333, Center Morphology, Mathematics, Fontainbleau, France.

Gunnarsson F, Holm S, Holmgren P, Thuresson T (1998). On the potential of kriging for forest management planning. Scandinavian Journal of Forest Research 13: 237-245. - doi: 10.1080/028 27589809382981

Haywood A (2011). Semi-automating the stand delineation process in mapping natural eucalypt forests. Australian Forestry 74 (1): 13-22. - doi: 10.1080/00049158.2011.10676341

Heikkinen J (2006). Assement of uncertainty in spatially systematic sampling. Forest inventory, methodology and applications. Managing Forest Ecosystems 10 (1): 155-176. - doi: 10.1007/1-40 20-4381-3 10

Hengl T (2007). A practical guide to geostatistical mapping of environmental variables. EUR 22904 EN Scientific and Technical Research Series no. 143, Office for Official Publications of the European Communities, Luxemburg, Belgium.

Hofierka J, Parajka J, Mitasova H, Mitas L (2002). Multivariate interpolation of precipitation using regularized spline with tension. Transactions in GIS 6: 135-150. - doi: 10.1111/14679671.00101

Holmgren P, Thuresson T (1997). Applying objectively estimated and spatially continuous forest parameters in tactical planning to obtain dynamic treatment units. Forest Science 43: 317 326.

Huth A, Drechsler M, Köhler P (2005). Using multi-criteria decision analysis and a forest growth model to assess impacts of tree harvesting in Dipterocarp lowland rain forests. Forest Ecology and Management 207: 215-232. - doi: 10.1016/j.foreco.2004.10.028

Höck BK, Payn TW, Shirley JW (1993). Using a geographic information system and geostatistics to estimate site index of Pinus radiata for Kangaroo Forest, New Zealand. N. Z. J. Forrest. Science 23: 264-277.

Jost A (1993). Geostatistical analysis of sampling error for systematic sampling. Ph.D. thesis, University of Freiburg,Breisgau, Germany, pp. 113. [In German]

Kangas J, Kangas A (2005). Multiple criteria decision support in forest management-the approach, methods applied, and experiences gained. Forest Ecology and Management 207: 133-143. - doi: 10.1016/j.foreco.2004.10.023

Kangas A, Kangas J, Pykäläinen J (2001). Outranking methods as tools in strategic natural resources planning. Silva Fennica 35 (2): 215-227. [online] URL: http://www.metla.fi/silvafennica/ full/sf35/sf352215.pdf

Khadka C, Vacik H (2012). Use of multi-criteria analysis (MCA) for supporting community forest management. iForest 5: 60-71. - doi: 10.3832/ ifor0608-009

Kirschbaum MU, Watt MS (2011). Use of a process-based model to describe spatial variation in Pinus radiata productivity in New Zealand. Forest Ecology and Management 262: 1008-
1019. - doi: 10.1016/j.foreco.2011.05.036

Kovacs JM, Liu Y, Zhang C, Flores-Verdugo F, de-Santiago FF (2011). A field based statistical approach for validating a remotely sensed mangrove forest classification scheme. Wetlands Ecology and Management 19: 409-421. - doi: 10.1007/s11273-011-9225-3

Köhl M, Magnussen S, Marchetti M (2006). Sampling methods, remote sensing and GIS multiresource forest inventory. In: "Remote Sensing" (chapt. 4). Springer Verlag, Heidelberg, Germany.

Jayanath A, Gamini H (2009). A critical review of multi-criteria decision making methods with special reference to forest management and planning. Ecological Economics 68(10): 2535-2548.

Lappi J, Kangas A (2006). Use of additional information. In: "Forest inventory - Methodology and Application" (chapt. 7). Springer, The Hague,the Netherlands. pp. 107-117.

Li J, Heap AD (2008). A review of spatial interpolation methods for environmental ecientists. No. Record 2008/23, Geoscience Australia, Canberra, Australia

Li J, Heap AD (2011). A review of comparative studies of spatial interpolation methods in environmental sciences: Performance and impact factors. Ecological Informatics 6: 228-241. - doi: 10.1016/j.ecoinf.2010.12.003

Lovell JL, Jupp DJB, Newnham GJ, Coops NC, Culvenor DS (2005). Simulation study for finding optimal Lidar acquisition parameters for forest height retrieval. Forest Ecology and Management 214: 398-412. - doi: 10.1016/j.foreco. 2004.07.077

Magnussen S, Næsset E, Wulder MA (2009). Efficient multiresolution spatial predictions for large data arrays. Remote Sensing of Environment 109: 451-463. - doi: 10.1016/j.rse.2007.01.018

Mandallaz D (1991). A unified approach to sampling theory for forest inventory based on infinite population and super population models. Chair of forest management and planning, Swiss Federal Institute of Technology, Zurich, Switzerlands. - doi: 10.3929/ethz-a-000585900

Mendoza GA, Martins H (2006). Multi-criteria decision analysis in natural resource management: a critical review of methods and new modeling paradigms. Ecology and Forest Management 230: 1-206. - doi: 10.1016/j.foreco.2006. 03.023

Mitas L, Mitasova H (1999). Spatial interpolation. In: "Geographical information systems: principles, techniques, management and applications" (Longley P, Goodchild MF, Maguire DJ, Rhind DW eds). GeoInformation International, Wiley, pp. 481-492.

Mitasova H, Mitas L, Brown WM, Gerdes DP, Kosinovski I, Baker T (1995). Modeling spatially and temporally distributed phenomena: new methods and tools for GRASS GIS. International Journal of Geographical Information Systems 9: 433. - doi: 10.1080/02693799508902 048

Mitasova H, Mitas L, Harmon RS (2005). Simultaneous spline approximation and topographic analysis for lidar elevation data in open-source GIS. Geoscience and Remote Sensing Letters IEEE 2: 375-379. - doi: 10.1109/LGRS.2005. 848533

Montes F, Alicia F, Ledo A (2010). Incorporating environmental and geographical information in forest data analysis: a new fitting approach for universal kriging. Canadian Journal of Forest Research 40 (9): 1852-1861. - doi: 10.1139/ $\mathrm{X} 10-131$

Nanos N, Calama R, Montero G, Gil L (2004). Geostatistical prediction of height/diameter models. Forest Ecology and Management 195: 221235. - doi: 10.1016/j.foreco.2004.02.031

Neteler M, Mitasova H (2008). Open Source GIS: a GRASS GIS approach. Kluwer. Academic Publishers/Springer, Boston, USA. pp.406.

Neteler M, Bowman MH, Landa M, Metz M (2012). GRASS GIS: a multi-purpose open source GIS. Environmental Modelling and Software 31: 124-130. - doi: 10.1016/j.envsoft.2011. 11.014

Palmer DJ, Höck BK, Kimberley MO, Watt MS, Lowe DJ, Payn TW (2009). Comparison of spatial prediction techniques for developing Pinus radiata productivity surfaces across New Zealand. Forest Ecology and Management 258: 2046-2055. - doi: 10.1016/j.foreco.2009.07.057 Perez-Soba M, Edwards D, Tabbush P (2006). Assessing the impacts of EU policies on sustainable forest management: the sensor approach. In: EFI Scientific Seminar "The role of Forestry in Integrated Environmental Assessment". Kerkade, 16/09/2006, The Netherlands.

Quantum GIS Development Team (2012). Quantum GIS geographic information system. Open Source Geospatial Foundation Project. [online] URL: http://qgis.osgeo.org

Schaffer C (1993). Selecting a classification method by cross-validation. Machine Learning 13 (1): 135-143. - doi: 10.1023/A:1022639714137 Shao J (1993). Linear model selection by crossvalidation. Journal of the American Statistical Association 88: 486-494. - doi: 10.1080/ 01621459.1993.10476299

Sherman M (1996). Variance estimation for statistics computed from spatial lattice data. Journal of the Royal Statistical Society 58: 509-523. [online] URL: http://www.jstor.org/stable/2345890

Smart LS, Swenson JJ, Christensen NL, Sexton JO (2012). Three-dimensional characterization of pine forest type and red-cockaded woodpecker habitat by small-footprint, discrete-return Lidar. Forest Ecology and Management 281:100-110. doi: $10.1016 /$ j.foreco.2012.06.020

Sobrie O (2010). Integration of ELECTRE TRI in a GIS coupling with a XMCDA web service for inference. In: Proceedings of the $73^{\text {rd }}$ Meeting of the European Working Group "Multiple Criteria Decision Aiding". $8^{\text {th }}$ Decision Deck Workshop. University of Mons (Belgium) 13 April 2011. [online] URL: http://mcda.univ-corse.fr/file/105 231/

Tang D, Bian F (2009). Forest site evaluation based on GIS and kriging. In: ICISE '09 Proceedings of the "2009 First IEE International 
Conference on Information Science and Engineering". Nanjing, Jiangsu China, December 26December 28, IEEE Computer Society Washington, DC, USA, pp. 2063-2067.

Tattoni C, Ciolli M, Ferretti F, Cantiani MG (2010). Monitoring spatial and temporal pattern of Paneveggio forest (northern Italy) from 1859 to 2006. iForest 3 (1): 72-80. - doi: 10.3832 ifor0530-003

Tattoni C, Ciolli M, Ferretti F (2011). The fate of priority areas for conservation in protected areas: a fine-scale Markov chain approach. Environmental Management 47: 263-278. - doi 10.1007/s00267-010-9601-4

Tattoni C, Rizzolli F, Pedrini P (2012). Can LiDAR data improve bird habitat suitability models? Ecological Modelling 245: 103-110. doi: 10.1016/j.ecolmodel.2012.03.020

Tuominen S, Fish S, Poso S (2003). Combining remote sensing, data from earlier inventories and geostatistical interpolation in multi-source forest inventory. Canadian Journal of Forest Research 33: 624- 634. - doi: 10.1139/x02-199

Viana H, Aranha J, Lopes D, Cohen WB (2012). Estimation of crown biomass of Pinus pinaster stands and shrubland above-ground biomass using forest inventory data, remotely sensed imagery and spatial prediction models. Ecological Modelling 226: 22-35. - doi: 10.1016/j.ecolmodel.2011.11.027

Wallerman J, Joyce S, Vencatasawmy CP, Olsson $H$ (2002). Prediction of forest stem volume using kriging adapted to detected edges. Canadian Journal of Forest Research 32: 509-518. - doi: 10.1139/x01-214

Wilsey CB, Joshua J, Lawler JJ, David A, Cimprich DA (2012). Performance of habitat suitability models for the endangered black-capped vireo built with remotely-sensed data. Remote Sensing of Environment 119:35-42. - doi: 10. 1016/j.rse.2011.12.002

Zawadzki J, Cieszewski CJ, Zasada M, Lowe RC (2005). Applying geostatistics for investigations of forest ecosystems using remote sensing imagery. Silva Fennica 39 (4): 599-617. [online] URL: http://www.metsantutkimuslaitos.fi/silvafennica/full/sf39/sf394599.pdf 